\title{
Fabrication of array of micro circular impressions using different electrolytes by maskless electrochemical micromachining
}

\author{
S. Kunar ${ }^{1,}$, E. Rajkeerthi ${ }^{2}$, K. Mandal ${ }^{3}$, and B. Bhattacharyya ${ }^{3}$ \\ ${ }^{1}$ Mechanical Engineering Department, Durgapur Institute of Advanced Technology and Management, Durgapur, India \\ ${ }^{2}$ Manufacturing Engineering Department, College of Engineering, Guindy, India \\ ${ }^{3}$ Production Engineering Department, Jadavpur University, Kolkata, India
}

Received: 31 January 2020 / Accepted: 17 March 2020

\begin{abstract}
Maskless electrochemical micromachining (EMM) is a prominent technique for producing the array of micro circular impressions. A method for producing the array of micro circular impressions on stainless steel workpiece applying maskless electrochemical micromachining process is presented. The experimental setup consists of maskless EMM cell, electrode holding devices, electrical connections of electrodes and constricted vertical cross flow electrolyte system to carry out the experimental investigation. One non-conductive masked patterned tool can produce more than twenty six textured samples with high quality. A mathematical model is developed to estimate theoretically the radial overcut and machining depth of the generated array of micro circular impressions by this process and corroborate the experimental results. This study provides an elementary perceptive about maskless EMM process based on the effects of EMM process variables i.e. pulse frequency and duty ratio on surface characteristics including overcut and machining depth for $\mathrm{NaCl}, \mathrm{NaNO}_{3}$ and $\mathrm{NaNO}_{3}+\mathrm{NaCl}$ electrolytes. From the experimental investigation, it is observed that the combined effect of lower duty ratio and higher frequency generates the best array of micro circular impressions using the mixed electrolyte of $\mathrm{NaNO}_{3}+\mathrm{NaCl}$ with mean radial overcut of $23.31 \mu \mathrm{m}$ and mean machining depth of $14.1 \mu \mathrm{m}$.
\end{abstract}

Keywords: Array of micro circular impressions / Maskless EMM / Electrolytes / Reused masked tool / Overcut / Machining depth

\section{Introduction}

Maskless EMM process is a prominent advanced micromachining technique for many advanced applications involving microsurface texturing containing array of micro circular impressions in the manufacturing of ultra-precision parts. Functional textures on stainless steel exploit significant chemical and physical phenomena on the surfaces at the micro and nano scale in the improvement of many sophisticated fields like information technology, tribology, biology, electronics, energy, biomimetics and optics [1]. However, microsurface structuring in many advanced fields still face two major problems viz. proper design of textured tools for microtexturing to be beneficial and requirement of economical microsurface texturing method to be designed on inexpensive components for mass production. But, maskless EMM is an economical method for fabricating the array of micro circular impressions with high quality using reusable masked patterned tool.

\footnotetext{
* e-mail: sandip.sandip.kunar@gmail.com
}

Many micromachining technologies involve fabricating the microsurface textures with controlled dimensional geometry. Bulk 3D microstructures have generated on cylindrical objects using lithography process. Then, through mask EMM (TMEMM) is applied to fabricate the controlled microstructures over large surface area of the cylinder using 10 wt. $\% \mathrm{NaCl}+10$ wt. $\% \mathrm{NaNO}_{3}$ electrolyte [2]. In this method, lithography is utilized to fabricate the patterned samples on non-planner surfaces, which is costly process for fabrication of many patterned samples. Effects of structured electrode is investigated on surface patterning by TMEMM method mathematically and experimentally using 10 wt. $\% \mathrm{NaCl}+10$ wt. $\% \mathrm{NaNO}_{3}$ electrolyte [3]. TMEMM is utilized to fabricate well-defined surface textures using $3 \mathrm{M}$ sulfuric acid. The shape change from electrochemical etching is numerically simulated using the boundary element method and it is satisfied experimentally with simulated etched profiles [4]. The array of micro impressions is produced by TMEMM process using $10 \%$ $\mathrm{NaNO}_{3}$ electrolyte and investigational outcome demonstrates the significance of electrical conductivity and pulse power for machining consistency over large area [5]. 
The micro dimple array is generated by TMEMM process using 1,2 and $3 \mathrm{M} \mathrm{NaCl}+1 \mathrm{M}$ glycerin electrolyte [6]. TMEMM method is proposed for the production of array of micro impressions using very thin masks. Experiments are carried out to study the effect of duty ratio on the undercut, surface roughness and etching factor of dimple pattern [7]. Through mask electrochemical micromachining is expensive and lengthy process for production of the array of micro impressions because every workpiece needs individual masking before machining. Higher concentration of electrolyte is uneconomical for the geometric accuracy of machined profiles because it increases the stray current effect during anodic dissolution. Sandwich like EMM is utilized to manufacture the array of micro impressions using $100 \mathrm{~g} / 1 \mathrm{NaNO}_{3}$ electrolyte [8]. This method deteriorates the quality of the fabricated micro dimples due to lack of flow of electrolyte. Higher concentration of electrolyte lowers the dimensional accuracy of the array of micro impressions due to higher electrolyte conductivity. Electrochemical jet processing method is employed for large area microtexturing and micro-milling using higher electrolyte concentration of $\mathrm{NaCl}, \mathrm{NaNO}_{3}$ and $\mathrm{NaI}$ [9]. This method is expensive process because it fabricates one by one structure. Higher concentration of electrolyte diminishes the quality of surface structures due to higher concentration of electrolyte which is responsible for higher stray current effect. Electrochemical process is used to produce the textured micropatterns on an unpatterned workpiece using $0.5 \mathrm{M} \mathrm{H}_{2} \mathrm{SO}_{4}$ and $0.5 \mathrm{M} \mathrm{CuSO}_{4}$ electrolyte [10]. The machining depth of generated micropatterns is very less. The conductive mask jet electrochemical machining method is employed to reduce the undercut of the array of micro impressions and improve the machining localization [11]. But, this method is prolonged and expensive due to fabrication of one by one circular impression in the micro dimple array. Electrochemical texturing is used for microtexturing using electrolyte concentration of $200 \mathrm{~g} / \mathrm{l} \mathrm{NaCl}$. Electrical discharge machining (EDM) technique is used to fabricate the textured tools [12]. EDM process may deteriorate the geometric profiles of the fabricated tools due to heat affected zone of EDM process. Maskless EMM is used to generate the varactor micropattern using the mixed electrolyte of $\mathrm{NaCl}$ $(5.8 \mathrm{M})$ and $\mathrm{NaNO}_{3}(8.5 \mathrm{M})$ and the effect of EMM process parameters are investigated on machining depth and material removal rate during fabrication of varactor micropattern [13]. The generated varactor micropattern is very complex. Higher concentration of electrolyte is not appropriate because it deteriorates the dimensional accuracy of the generated varactor micropattern due to higher stray current effect. The influence of major EMM parameters, i.e. machining voltage, inter-electrode gap, flow rate and machining time are investigated on width overcut and machining depth of linear and cascade micropatterns [14]. The influences of major process parameters are explored on major and minor axis overcuts, machining depth and surface roughness $\left(R_{a}\right)$ using hydrostatic and three different electrolyte flow methods during micro ellipse pattern generation [15]. The influence of inter electrode gap, applied voltage and flow rate is investigated on textured characteristics i.e. machining depth, overcut and surface roughness $\left(R_{a}\right)$ using six types of masked patterned tools during maskless micro-electrochemical texturing process [16].

Various techniques are also offered for the generation of microsurface textures such as LIGA technology, electron beam machining, through mask electrochemical micromachining, laser beam machining, ion beam machining, etc. However, these methods are incapable of the demands of economical microsurface structures in industrial manufacturing that can be generated in mass production [17]. These methods have several limitations such as heat affected zone, lower machining accuracy, lower surface finish, etc.

Therefore, maskless EMM is a significant alternative method due to its important benefits such as no heat affected zone, high machining rate, good surface finish, machinability of intricate shapes regardless of their hardness and toughness, reusability of a masked patterned tool, forceless machining, etc. It offers also no mask removal process from machined workpiece, no chance of degradation of surface quality and higher productivity for the reusable single masked patterned tool, etc. which are involved in through mask EMM.

An alternative method of maskless EMM is applied for the generation of array of micro circular impressions. In this research study, the maskless EMM setup is indigenously developed for conducting the experiments. One patterned masked tool can generate a lot of machined samples with high quality. The influences of EMM process variables i.e. duty ratio and pulse frequency on micro circular patterned geometrics namely, overcut and depth for three different electrolytes i.e. $\mathrm{NaNO}_{3}, \mathrm{NaCl}$ and $\mathrm{NaNO}_{3}+\mathrm{NaCl}$ are investigated. A numerical model is developed to calculate the machining depth and radial overcut of the generated array of micro circular impressions theoretically using EMM process parameters and validated with the experimental results. An effort has also been done to analysis the textured responses of generated dimple pattern for getting the best parametric setting.

\section{Experimental procedure}

A well planned maskless EMM setup has been developed for conducting the experimental investigation. The experimental setup consists of maskless EMM cell, constricted vertical cross flow electrolyte system, tool and workpiece fixtures, and electrical connections of tool and workpiece as shown in Figure 1. Perspex material is used to generate the maskless EMM cell as shown in Figure 2. Perspex is suitable material for this cell due to its transparent, corrosion resistance, higher strength properties, etc. The cell material has also higher strength and endures the higher electrolyte flow rate. Stainless steel material is utilized to produce the outlet and inlet ports of the cell to avoid the corrosion from environment. Perspex is also used to make the electrode fixtures. These fixtures have higher strength to hold the tool and workpiece properly during machining operation. The gear pump is used to supply the electrolyte through the constricted path between workpiece and tool from downward to upward 


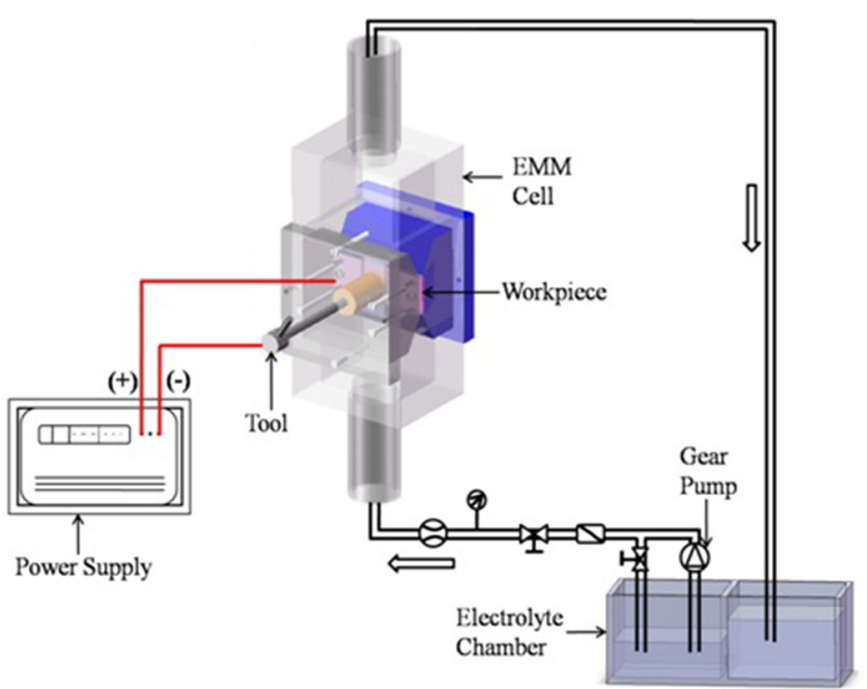

Fig. 1. Maskless EMM setup.

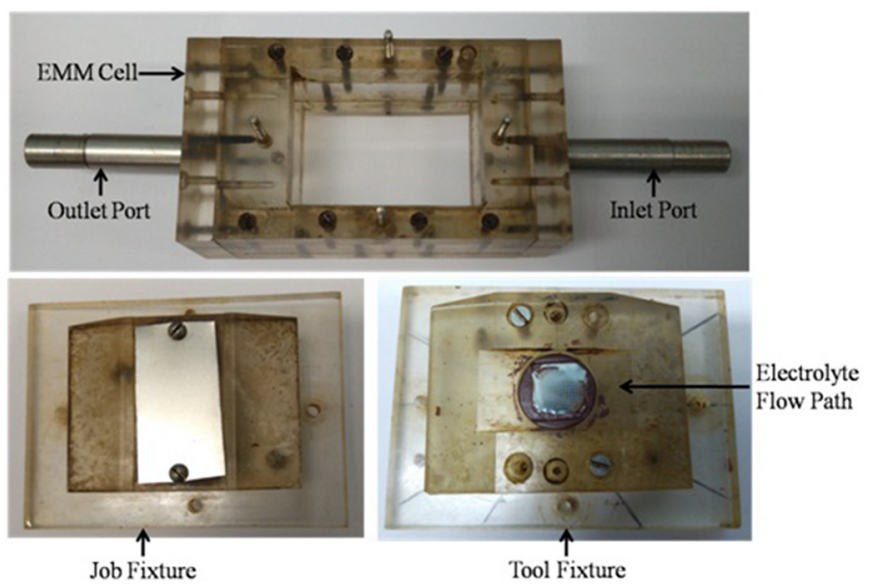

Fig. 2. Developed maskless EMM cell with tool and workpiece fixtures.

directions. Electrolyte flow is controlled by flow control valves. Extra electrolyte flow is bypassed to the tank. In this flow system, vertical cross flow electrolyte circulation system is the most important feature in which electrolyte flow is parallel to the workpiece and tool and feeds vertically. This flow produces extra back pressure, which aids to eradicate the electrolysis products and supplies always fresh electrolyte in the micromachining zone. The generated geometric profiles and accuracy of surface textures are also better than other electrolyte flow methods. The DC pulsed power supply is employed to supply the pulse current during machining, which is prepared with protection functions and in-built function generator.

SU-8 2150 mask (MicroChem, USA) is employed to produce the array of micro circular impressions on SS-304 sheets using UV exposure system for conducting the experiments. The average diameter of micro circular pattern is $385 \mu \mathrm{m}$ with mask thickness of $220 \mu \mathrm{m}$. The gap between two successive impressions across the margin is $800 \mu \mathrm{m}$. A small copper is attached with the textured tool using conductive adhesive silver paste and the arrangements of tool is fastened with precession micrometer to control the inter electrode gaps in this process. The masked tool having array of micro holes are used in for a variety of electronic applications including information display, electronic paper and radio frequency identification.

The fabricated tool is utilized to produce the array of micro circular impressions in the developed setup using $\mathrm{NaNO}_{3}, \mathrm{NaCl}$ and $\mathrm{NaNO}_{3}+\mathrm{NaCl}$ electrolytes. Before conducting the final experimental investigation, the extensive trial experiments are performed to choose the important EMM parameters for the generation of array of micro circular impressions by $\mathrm{NaNO}_{3}, \mathrm{NaCl}$ and $\mathrm{NaNO}_{3}+$ $\mathrm{NaCl}$ electrolytes. Based on extensive trial experiments, two most significant EMM parameters i.e. duty ratio and pulse frequency are considered for experimentation and final experiments are conducted by changing one parameter at a time with other fixed parameters on the basis of good investigational results. $\mathrm{NaNO}_{3}, \mathrm{NaCl}$ and $\mathrm{NaNO}_{3}+$ $\mathrm{NaCl}$ have been preferred to study the performance of electrolytes on microsurface textured responses and anodic dissolution capability of stainless steel (SS-304) has been investigated during generation of array of micro circular impressions using $\mathrm{NaNO}_{3}(0.17 \mathrm{M}), \mathrm{NaCl}(0.25 \mathrm{M})$, and $\mathrm{NaNO}_{3}(0.17 \mathrm{M})+\mathrm{NaCl}(0.25 \mathrm{M})$ electrolytes. Three types of electrolytes are employed for methodical investigation of the suitability of electrolytes for better machined responses of micro circular patterns by maskless electrochemical micromachining. The ranges of duty ratio and pulse frequency are $30 \%$ to $60 \%$ and $5 \mathrm{kHz}$ to $20 \mathrm{kHz}$ respectively and other fixed parameters are inter electrode gap of $50 \mu \mathrm{m}$, applied voltage of $8 \mathrm{~V}$, flow rate of $6.12 \mathrm{~m}^{3} / \mathrm{hr}$ and machining time of 2 minutes. The generated micro circular impressions are not uniform and most of circular impressions are not formed below the above mentioned parametric ranges. The dimensional accuracy of micro circular impressions deteriorates beyond the above mentioned parametric ranges. Electrical resistance is measured by the conductivity meter. The standard deviations of radial overcut and depth are also computed to find out the quality of array of micro circular impressions. The textured characteristics are measured with Atomic Force Microscope (Nanosurf Easyscan 2, Switzerland), Optical Microscope (Leica DM2500, Germany) and 3D NonContact Profilometer.

\section{Development of mathematical model}

Two important EMM process variables i.e. pulse frequency and duty ratio directly affect the radial overcut and machining depth. These process parameters can control suitably to obtain the required machining depth and overcut of the array of micro circular impressions. The machining depth and radial overcut can be determined successfully by the developed mathematical model.

Some assumptions are considered to calculate the theoretical radial overcut of micro circular pattern:

- Micro circular impression is regarded as a spherical segment of a sphere. 


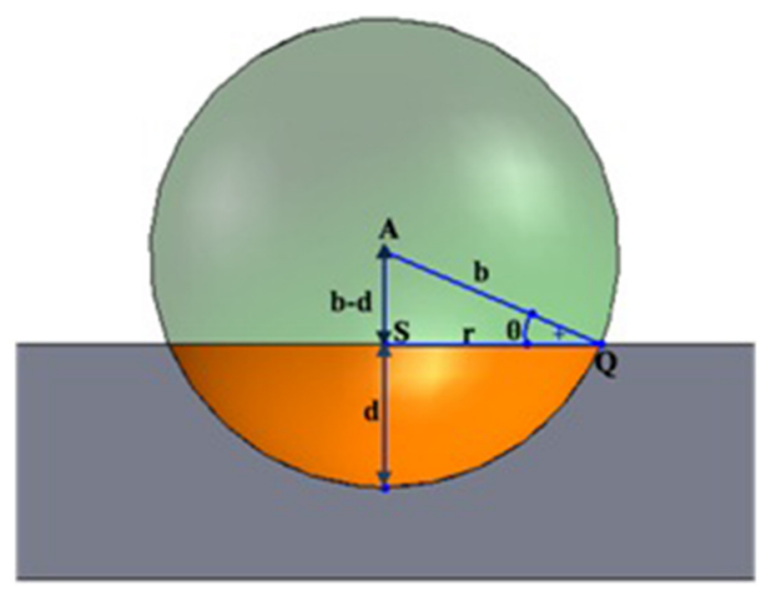

Fig. 3. Schematic diagram of a spherical cap.

- Micro circular impression is homogeneous in terms of depth and radial overcut and machining rate is uniform throughout the micro circular pattern.

The spherical cap of a circular impression is shown in Figure 3 and the radius of sphere is $b$. The depth and radius and cap angle of circular impression are $d, r$ and $\theta$ respectively.

The volume of spherical cap,

$$
v=\frac{\pi d^{2}}{3}(3 b-d) .
$$

Here,

$$
b=\frac{d}{1-\sin \theta}\left[0 \leq \theta<\frac{\pi}{2}\right] .
$$

From equations (1) and (2), the volume of cap,

$$
v=\frac{\pi d^{3}}{3}\left(\frac{2+\sin \theta}{1-\sin \theta}\right)
$$

So, the mass of material of removed from micro circular pattern

$$
n \times \rho \times \frac{\pi d^{3}}{3}\left(\frac{2+\sin \theta}{1-\sin \theta}\right)
$$

where, total number of circular impressions in micro circular pattern is $n$ and density of material is $\rho$.

As per Faraday's law, the total mass of material removed

$$
\mathrm{M}=\mathrm{EIT}
$$

where

$$
E=\frac{A}{z F}=\text { Electrochemical equivalent }
$$

where, the atomic weight is $A$, the machining current is $I$, the machining time is $T$, the valency is $z$ and Faraday's constant is $F$.
As per Ohm's law, $\mathrm{V}=\mathrm{IR}$, where, the potential difference is $V$ and the resistance is $R$.

$$
R=\frac{\sigma L}{a}
$$

where, the resistivity of electrolyte is $\sigma$, the inter electrode gap is $L$, the machining area is a, through which electrolyte is passed with flow velocity of $\mathrm{S}$ and $Q$ is the flow rate. So, $Q=a X S$

Now, from equation (5),

$$
M=\frac{E V T Q}{\sigma S L} .
$$

Therefore, the material removal during on-time,

$$
M_{\mathrm{on}}=\int_{0}^{t_{o n}} \frac{E V T Q}{\sigma S L} d t=\frac{E V Q t_{o n}}{\sigma S L} .
$$

From equations (4) and (7), the depth of micro circular pattern,

$$
d=\sqrt[3]{\frac{3 E V Q t_{\text {on }}(1-\sin \theta)}{\pi n \rho \sigma S L(2+\sin \theta)}} .
$$

Now,

$$
\sigma=\frac{1}{K}, K=A_{m} C, D=\frac{t_{o n}}{T} \text { and } T=\frac{1}{F}
$$

where, the conductivity of electrolyte is $K$, the molar conductivity is $A_{m}$, the concentration of electrolyte is $C$, duty ratio is $D$, the pulse period is $T$ and the frequency is $F$.

So, equation (8) will be

$$
d=\sqrt[3]{\frac{3 E V D Q C A_{m}(1-\sin \theta)}{\pi n \rho S L F(2+\sin \theta)}} .
$$

Equation (9) provides the relationship of the depth of micro circular pattern between pulse frequency and duty ratio, where the depth increases with increasing duty ratio and the depth decreases with increasing pulse frequency.

Again, for estimation of theoretical overcut of micro circular pattern:

The volume of spherical cap,

Here,

$$
v=\frac{\pi d^{2}}{3}(3 b-d)
$$

$$
b=\frac{r}{\cos \theta}=\frac{P+R}{\cos \theta}\left[0 \leq \theta<\frac{\pi}{2}\right]
$$

where, $P$ is the radius of circular impression of tool and $R$ is radial overcut of machined circular impression.

So, the total material removed $=$

$$
n \rho \frac{\pi d^{2}}{3}(3 b-d) .
$$

From equation (7), the total mass of material removed as per Faraday's law

$$
M_{o n}=\int_{0}^{t_{o n}} \frac{E V T Q}{\sigma S L} d t=\frac{E V Q t_{o n}}{\sigma S L} .
$$




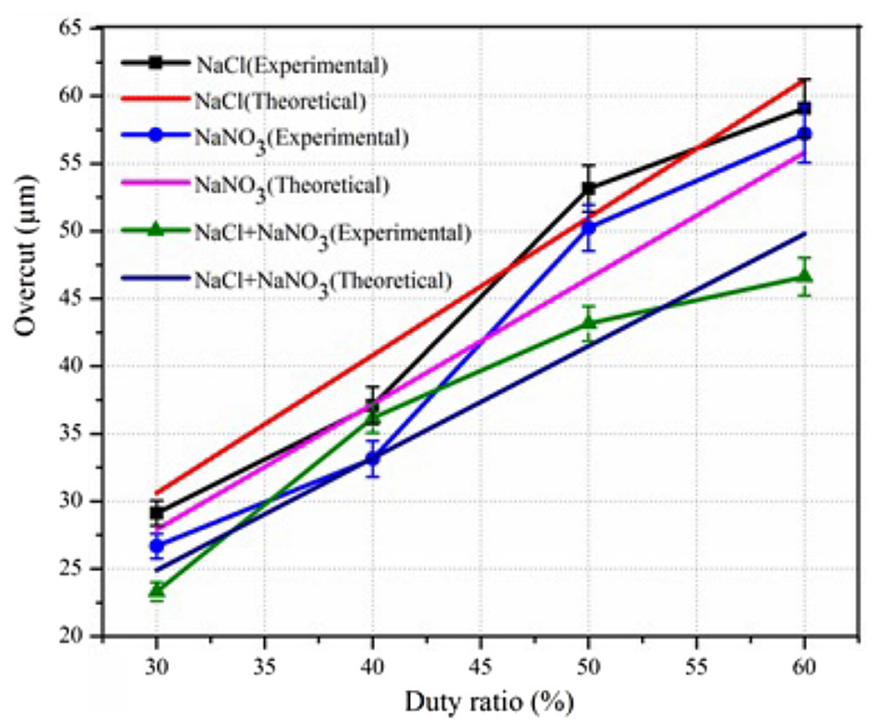

Fig. 4. Influence of duty ratio on overcut.

Now,

$$
\sigma=\frac{1}{K}, K=A_{m} C, D=\frac{t_{o n}}{T} \text { and } T=\frac{1}{F} .
$$

From equations (11), (12) and (13), the required radial overall overcut

$$
R=\left(\frac{E V Q D C A_{m} \cos \theta}{\pi n \rho d^{2} S L F}-P+\frac{d \cos \theta}{3}\right)
$$

Equation (14) provides that if the radial overcut increases with increasing duty ratio and the radial overcut decreases with increasing pulse frequency.

The developed mathematical model presents the estimation value of depth and radial overcut of micro circular pattern by co-relating the influence of important process parameters during micro circular pattern generation. This numerical model has been theoretically evaluated and validated with experimental results in this study.

\section{Experimental results and discussion}

The characteristics that describe the quality of a microtexture are radial overcut and machining depth. Experimental results are plotted in terms of various graphs and investigated keeping in mind the objectives of shape and size control with less overcut and controlled depth of micro circular pattern using suitable electrolyte.

\subsection{Influence of process parameters on micro circular pattern}

Experiments are performed to show the effects of duty ratio on radial overcut with constant pulse frequency of $20 \mathrm{kHz}$ using reusable patterned tool. The comparision between experimental and theoretical results for three different electrolytes with respect to duty ratio as shown in Figure 4.
With increase in duty ratio the experimental overcut increases for $\mathrm{NaNO}_{3}, \mathrm{NaCl}$ and $\mathrm{NaNO}_{3}+\mathrm{NaCl}$ electrolytes owing to higher stray current effect in higher machining time for higher duty ratio. For $\mathrm{NaNO}_{3}$, the overcut lies between $\mathrm{NaCl}$ and $\mathrm{NaNO}_{3}+\mathrm{NaCl}$ except duty ratio of $40 \%$ because of lower stray current effect for lower electrical conductivity compared to $\mathrm{NaCl}$. At duty ratio of $40 \%$, the lowest radial overcut is observed for $\mathrm{NaNO}_{3}$ due to controlled ectching. In case of $\mathrm{NaCl}$, The overcut is higher than $\mathrm{NaNO}_{3}$ and $\mathrm{NaNO}_{3}+\mathrm{NaCl}$ due to higher electrical conductivity. In case of $\mathrm{NaCl}+\mathrm{NaNO}_{3}$, lower overcut is achieved than $\mathrm{NaCl}$ and $\mathrm{NaNO}_{3}$ without duty ratio of $40 \%$ because of higher machining rate of $\mathrm{NaCl}$ and higher machining accuracy of $\mathrm{NaNO}_{3}$. At duty ratio of $40 \%$, the overcut locates in-between $\mathrm{NaNO}_{3}$ and $\mathrm{NaCl}$ due to nonuniform machining. The standard deviations of radial overcut are lower at $30 \%$ duty ratio for three different electrolytes. Among these three electrolytes, the lowest standard deviation has been observed for $\mathrm{NaCl}+\mathrm{NaNO}_{3}$ electrolyte.

The theoretical overcut increases with increasing duty ratio for three different electrolytes as per developed equation (14). The experimental overcut also increases with increasing duty ratio for three electrolytes as per developed equation (14). For $\mathrm{NaCl}$, the experimental overcut is deviated equal or less than $2.7 \mu \mathrm{m}$ from the theoretical graph. For $\mathrm{NaNO}_{3}$, the experimental overcut is deviated equal or less than $4.1 \mu \mathrm{m}$ from the theoretical graph. For $\mathrm{NaCl}+\mathrm{NaNO}_{3}$, the experimental overcut is deviated equal or less than $3.1 \mu \mathrm{m}$ from the theoretical graph. The developed equation (14) is used for the initial estimation of theoretical radial overcut of the array of micro circular impressions for various duty ratios and validates the experimental results. The overcut and machining depth of three electrolytes for different duty ratios have been shown in Tables $1-3$.

Influence of duty ratio on the machining depth is shown in Figure 5 and it reveals the evaluation between the experimental and theoretical depths of the micro circular pattern for three different electrolytes with other constant parameter of pulse frequency of $20 \mathrm{kHz}$. From the graph, it is clear that with increasing duty ratio the experimental depth increases. It is because higher pulse on time i.e. higher machining time is acquired than pulse off-time in higher duty ratio and controlled machining localization takes place for higher current density. The localization effect increases because the electrolysis products can be flushed away by the flow of electrolyte during the pulse offtime and makes the ready for machining during the pulseon time. In case of $\mathrm{NaNO}_{3}$, the depth occupies the middle zone in-between $\mathrm{NaCl}$ and $\mathrm{NaCl}+\mathrm{NaNO}_{3}$ due to controlled electrical conductivity compared to $\mathrm{NaCl}$. In case of $\mathrm{NaCl}$, the machining depth is lower than $\mathrm{NaCl}+\mathrm{NaNO}_{3}$ and $\mathrm{NaNO}_{3}$ electrolytes due to the higher metallic ions. In case of $\mathrm{NaCl}+\mathrm{NaNO}_{3}$, higher machining depth is observed than $\mathrm{NaCl}$ and $\mathrm{NaNO}_{3}$ owing to controlled etching. The standard deviations of machining depth is lower at $30 \%$ duty ratio for three different electrolytes. Aomng them, the lowest standard deviation and uniformity of micro circular pattern have been shown at duty ratio of $30 \%$ for $\mathrm{NaCl}+\mathrm{NaNO}_{3}$ electrolyte. 
Table 1. Overcut and machining depth for $\mathrm{NaCl}+\mathrm{NaNO}_{3}$ electrolyte.

\begin{tabular}{lllll}
\hline $\begin{array}{l}\text { Duty } \\
\text { ratio }\end{array}$ & $\begin{array}{l}\text { Overcut } \\
(\text { Theoretical) } \\
\mathrm{NaCl}+\mathrm{NaNO}_{3}\end{array}$ & $\begin{array}{l}\text { Overcut } \\
\text { (Experimental) } \\
\mathrm{NaCl}+\mathrm{NaNO}_{3}\end{array}$ & $\begin{array}{l}\text { Depth } \\
\text { (Theoretical) } \\
\mathrm{NaCl}+\mathrm{NaNO}_{3}\end{array}$ & $\begin{array}{l}\text { Depth } \\
\text { (Experimental) } \\
\mathrm{NaCl}^{-\mathrm{NaNO}_{3}}\end{array}$ \\
\hline 30 & 24.9 & 23.31 & 15.4 & 14.1 \\
40 & 33.2 & 36.16 & 20.4 & 22.6 \\
50 & 41.5 & 43.15 & 25.5 & 24.2 \\
60 & 49.8 & 46.62 & 30.6 & 31.5 \\
\hline
\end{tabular}

Table 2. Overcut and machining depth for $\mathrm{NaCl}$ electrolyte.

\begin{tabular}{lllll}
\hline $\begin{array}{l}\text { Duty } \\
\text { ratio }\end{array}$ & $\begin{array}{l}\text { Overcut } \\
\text { (Theoretical) }\end{array}$ & $\begin{array}{l}\text { Overcut } \\
\text { (Experimental) }\end{array}$ & $\begin{array}{l}\text { Depth } \\
\text { (Theoretical) }\end{array}$ & $\begin{array}{l}\text { Depth } \\
\text { (Experimental) } \\
\text { NaCl }\end{array}$ \\
\hline 30 & 30.6 & 29.12 & 13.1 & 11.6 \\
40 & 40.8 & 37.1 & 17.2 & 16.8 \\
50 & 51 & 53.15 & 21.5 & 19.6 \\
60 & 61.2 & 59.07 & 25.8 & 21.7 \\
\hline
\end{tabular}

Table 3. Overcut and machining depth for $\mathrm{NaNO}_{3}$ electrolyte.

\begin{tabular}{lllll}
\hline $\begin{array}{l}\text { Duty } \\
\text { ratio }\end{array}$ & $\begin{array}{l}\text { Overcut } \\
(\text { Theoretical) }\end{array}$ & $\begin{array}{l}\text { Overcut } \\
\text { (Experimental) } \\
\mathrm{NaNO}_{3}\end{array}$ & $\begin{array}{l}\text { Depth } \\
\text { (Theoretical) } \\
\mathrm{NaNO}_{3}\end{array}$ & $\begin{array}{l}\text { Depth } \\
\text { (Experimental) } \\
\mathrm{NaNO}_{3}\end{array}$ \\
\hline 30 & 27.9 & 26.68 & 14.3 & 12.8 \\
40 & 37.2 & 33.148 & 18.8 & 18.3 \\
50 & 46.5 & 50.251 & 23.5 & 21.5 \\
60 & 55.8 & 57.201 & 28.2 & 28.7 \\
\hline
\end{tabular}

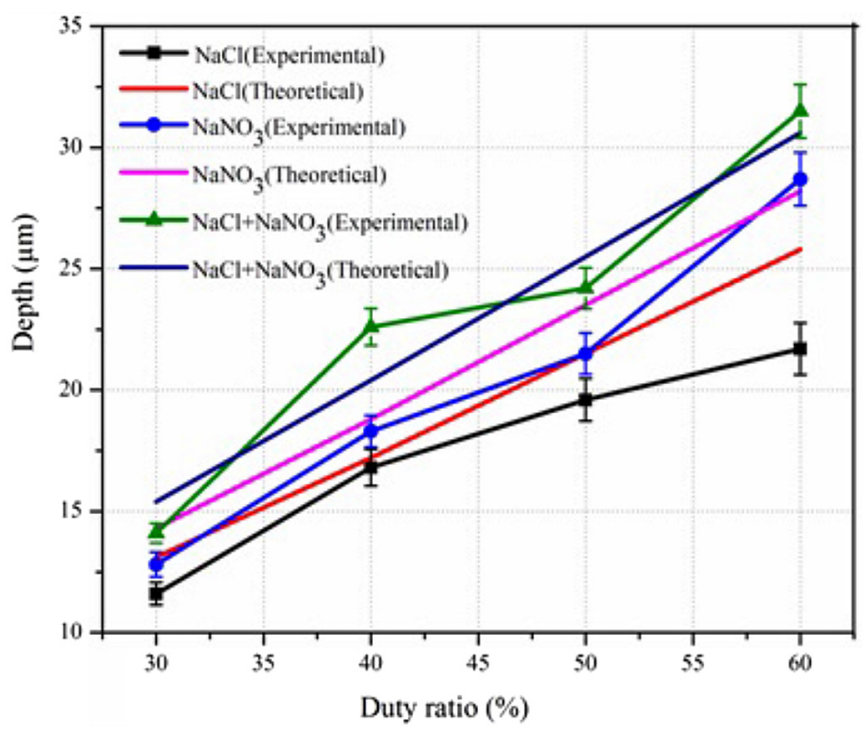

Fig. 5. Influence of duty ratio on machining depth.
The theoretical and experimental depths increase as per developed equation (9). For $\mathrm{NaCl}$, the experimental depth is deviated equal or less than $4.1 \mu \mathrm{m}$ from the theoretical graph. For $\mathrm{NaNO}_{3}$, the experimental depth is deviated equal or less than $2 \mu \mathrm{m}$ from the theoretical graph. For $\mathrm{NaCl}+\mathrm{NaNO}_{3}$, the experimental depth is deviated equal or less than $2.2 \mu \mathrm{m}$ from the theoretical graph. The developed equation (9) is suitable for the preliminary determination of theoretical depth for various duty ratios and confirms the validation of experimental results.

Effect of frequency on experimental and theoretical overcuts is shown in Figure 6 and represents the comparisons between them. The experimental overcut decreases with increased pulse frequency for various electrolytes because the rate of repetition of pulse on time i.e. machining time decreases with increasing pulse frequency. The stray current effect also decreases for lower pulse on time in higher frequency. In case of $\mathrm{NaNO}_{3}$, the overcut locates in-between $\mathrm{NaNO}_{3}+\mathrm{NaCl}$ and $\mathrm{NaCl}$ due to controlled machining for lower metallic ions. In case of $\mathrm{NaCl}$, higher overcut is obtained than $\mathrm{NaNO}_{3}+\mathrm{NaCl}$ 


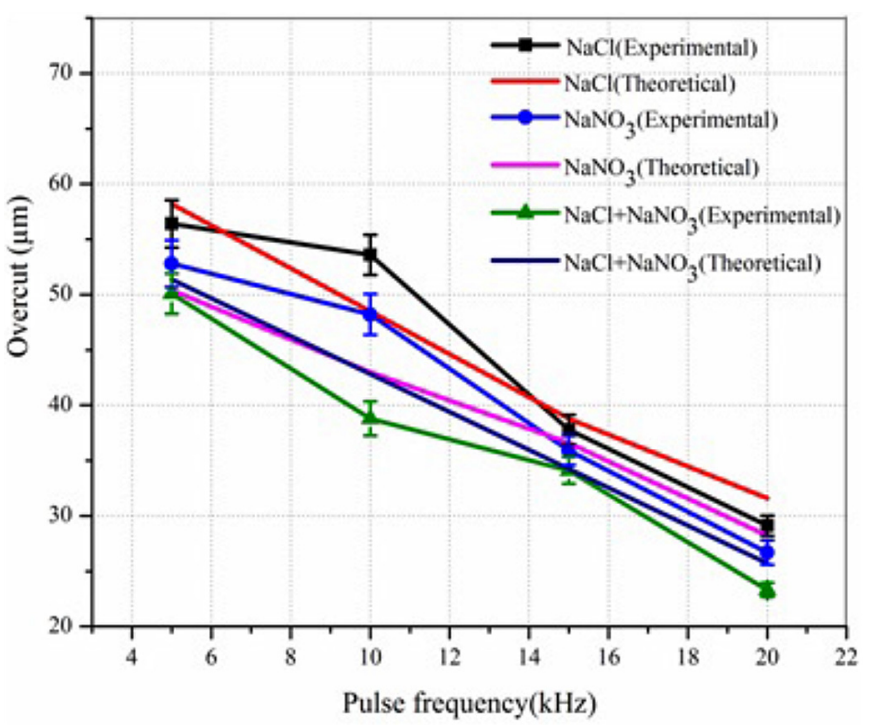

Fig. 6. Influence of pulse frequency on overcut.

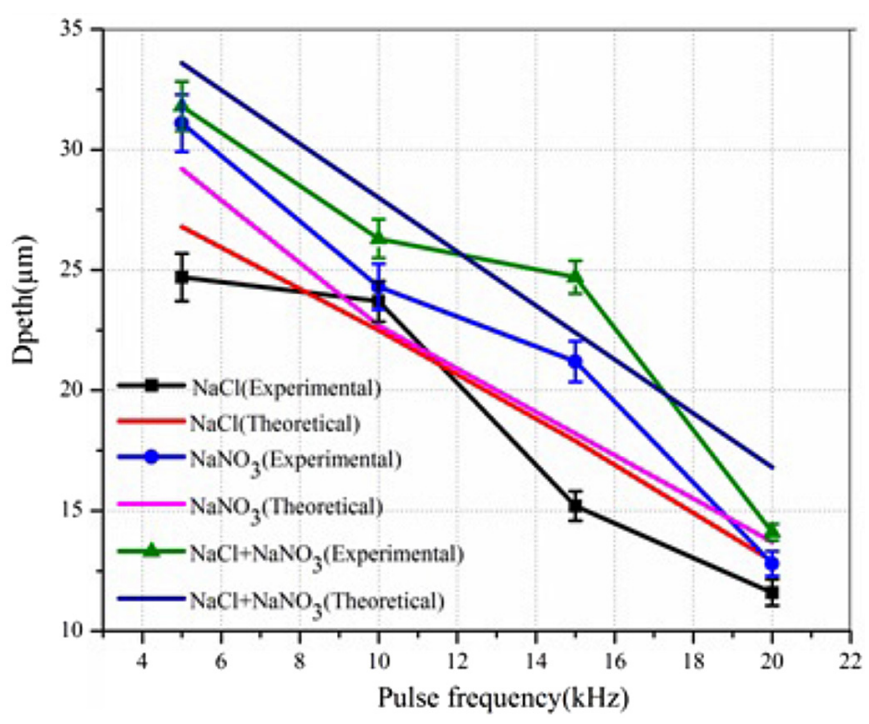

Fig. 7. Influence of pulse frequency on machining depth.

Table 4. Overcut and machining depth for $\mathrm{NaCl}+\mathrm{NaNO}_{3}$ electrolyte.

\begin{tabular}{lllll}
\hline Frequency & $\begin{array}{l}\text { Overcut } \\
(\text { Theoretical) } \\
\mathrm{NaCl}+\mathrm{NaNO}_{3}\end{array}$ & $\begin{array}{l}\text { Overcut } \\
\text { (Experimental) } \\
\mathrm{NaCl}+\mathrm{NaNO}_{3}\end{array}$ & $\begin{array}{l}\text { Depth } \\
\text { (Theoretical) } \\
\mathrm{NaCl}+\mathrm{NaNO}_{3}\end{array}$ & $\begin{array}{l}\text { Depth } \\
\text { (Experimental) } \\
\mathrm{NaCl}^{+} \mathrm{NaNO}_{3}\end{array}$ \\
\hline 5 & 51.38 & 53.1 & 33.6 & 31.8 \\
10 & 42.82 & 38.8 & 28 & 26.3 \\
15 & 34.26 & 35.1 & 22.4 & 24.7 \\
20 & 25.7 & 23.31 & 16.8 & 14.1 \\
\hline
\end{tabular}

Table 5. Overcut and machining depth for $\mathrm{NaCl}$ electrolyte.

\begin{tabular}{lllll}
\hline Frequency & $\begin{array}{l}\text { Overcut } \\
\text { (Theoretical) }\end{array}$ & $\begin{array}{l}\text { Overcut } \\
\text { (Experimental) }\end{array}$ & $\begin{array}{l}\text { Depth } \\
\text { (Theoretical) }\end{array}$ & $\begin{array}{l}\text { Depth } \\
\text { (Experimental) } \\
\text { NaCl }\end{array}$ \\
\hline 5 & $\mathrm{NaCl}$ & 56.4 & 26.8 & 24.7 \\
10 & 58.2 & 51.6 & 22.5 & 23.7 \\
15 & 48.5 & 35.8 & 17.9 & 15.2 \\
20 & 38.8 & 29.12 & 12.9 & 11.6 \\
\hline
\end{tabular}

and $\mathrm{NaNO}_{3}$ because of uncontrolled anodic dissolution for higher metallic ions. For $\mathrm{NaCl}+\mathrm{NaNO}_{3}$, lower overcut is acquired than $\mathrm{NaNO}_{3}$ and $\mathrm{NaCl}$ owing to uniform etching for controlled current distribution. The standard deviations of radial overcut are lower at pulse frequency of $20 \mathrm{kHz}$ for various electrolytes. Among them, the lowest standard deviation and regularity of micro circular pattern are shown at frequency of $20 \mathrm{kHz}$ for $\mathrm{NaNO}_{3}+\mathrm{NaCl}$ electrolyte.

Here, the theoretical and experimental overcuts decrease with increase in pulse frequency as per developed equation (14) for three different electrolytes. For $\mathrm{NaCl}$, the experimental overcut is deviated equal or less than $5.1 \mu \mathrm{m}$ from the theoretical overcut. For $\mathrm{NaNO}_{3}$, the experimental overcut is deviated equal or less than $5.2 \mu \mathrm{m}$ from the theoretical overcut. For $\mathrm{NaCl}+\mathrm{NaNO}_{3}$, the experimental overcut is deviated equal or less $4 \mu \mathrm{m}$ than the theoretical graph. The developed equation (14) is suitable for the primary determination of radial overcut of array of micro circular impressions for various pulse frequencies and corroborates the experimental results. The overcut and machining depth of three electrolytes for different pulsed frequencies have been shown in Tables 4-6.

The effect of frequency on the machining depth is shown in Figure 7 and represents the evaluation between the theoretical and experimental depths with fixed duty ratio 
Table 6. Overcut and machining depth for $\mathrm{NaNO}_{3}$ electrolyte.

\begin{tabular}{|c|c|c|c|c|}
\hline Frequency & $\begin{array}{l}\text { Overcut } \\
(\text { Theoretical) } \\
\mathrm{NaNO}_{3}\end{array}$ & $\begin{array}{l}\text { Overcut } \\
(\text { Experimental) } \\
\mathrm{NaNO}_{3}\end{array}$ & $\begin{array}{l}\text { Depth } \\
(\text { Theoretical) } \\
\mathrm{NaNO}_{3}\end{array}$ & $\begin{array}{l}\text { Depth } \\
(\text { Experimental }) \\
\mathrm{NaNO}_{3} \\
\end{array}$ \\
\hline 5 & 50.4 & 52.8 & 29.2 & 32.1 \\
\hline 10 & 43 & 46.2 & 22.7 & 23.8 \\
\hline 15 & 35.6 & 32.9 & 18.2 & 21.2 \\
\hline 20 & 28.2 & 26.68 & 13.7 & 12.8 \\
\hline
\end{tabular}

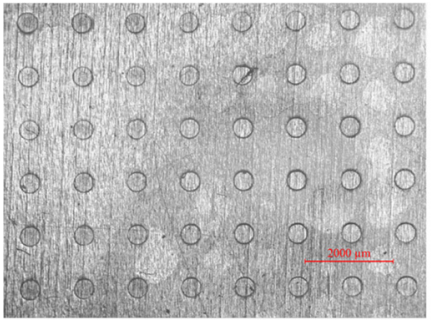

(a)

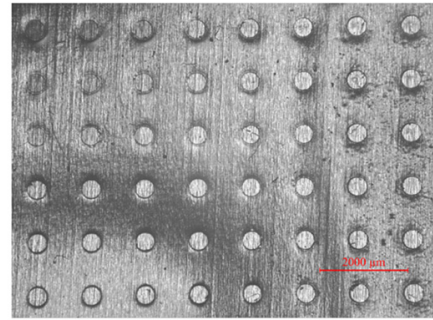

(b)
Fig. 8. (a) Unused masked pattern before machining; (b) used masked pattern after machining.

of $30 \%$. With increasing frequency the experimental depth decreases. The machining depth reduces owing to the availability of lower pulse on time in higher frequency than lower pulse frequency. Higher machining depth is observed at lower pulse frequency because the anodic dissolution takes place in controlled manner. In case of $\mathrm{NaNO}_{3}$, the machining depth occupies the middle zone in-between $\mathrm{NaCl}$ and $\mathrm{NaNO}_{3}+\mathrm{NaCl}$ because of controlled dissolution for lower electrical conductivity. In case of $\mathrm{NaCl}$, lower machining depth is achieved than $\mathrm{NaNO}_{3}$ and $\mathrm{NaNO}_{3}+$ $\mathrm{NaCl}$ because of uncontrolled dissolution for higher metallic ions. In case of $\mathrm{NaNO}_{3}+\mathrm{NaCl}$, higher depth is obtained than $\mathrm{NaNO}_{3}$ and $\mathrm{NaCl}$ because of higher machining localization for uniform current flux distribution. The standard deviations of machining depth are lower at frequency of $20 \mathrm{kHz}$ for $\mathrm{NaNO}_{3}, \mathrm{NaCl}$ and $\mathrm{NaNO}_{3}+$ $\mathrm{NaCl}$. Only $\mathrm{NaNO}_{3}+\mathrm{NaCl}$ electrolyte maintains the lowest standard deviation than other two electrolytes.

Here, the experimental and theoretical depths decrease with increasing pulse frequency as per developed equation (9) for three different electrolytes. For $\mathrm{NaCl}$, the experimental depth is deviated equal or less than $2.7 \mu \mathrm{m}$ from the theoretical overcut. For $\mathrm{NaNO}_{3}$, the experimental overcut is deviated equal or less than $3 \mu \mathrm{m}$ from the theoretical overcut. For $\mathrm{NaCl}+\mathrm{NaNO}_{3}$, the experimental overcut is deviated equal or less $2.7 \mu \mathrm{m}$ than the theoretical graph. Hence, the developed equation (9) is used for the preliminary evaluation of theoretical depth of the array of micro circular impressions for various pulse frequencies. Thus, it correlates with the equation (9) and experimental results.

\subsection{Analysis of micrographs}

Effects of process parameters on microtextured characteristics are studied for $\mathrm{NaNO}_{3}, \mathrm{NaCl}$ and $\mathrm{NaNO}_{3}+\mathrm{NaCl}$

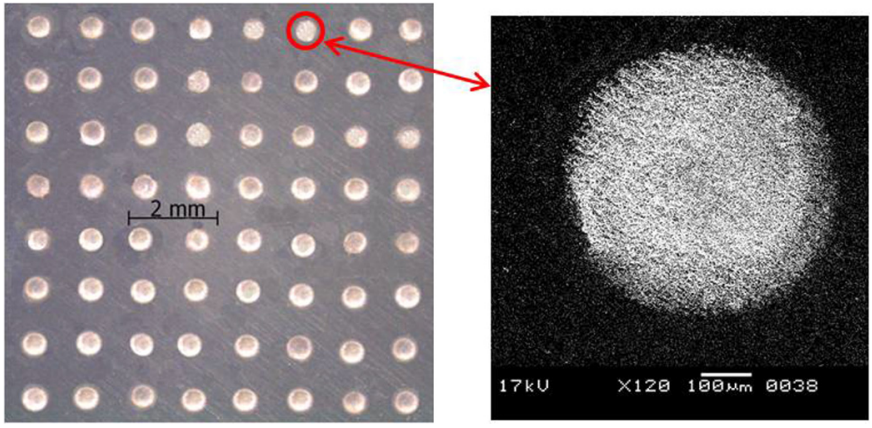

Fig. 9. Regular array of micro circular impressions generated by $\mathrm{NaCl}+\mathrm{NaNO}_{3}$.

electrolytes using SU-8 2150 photoresist tool. This photoresist has enough strength to fabricate more than twenty six machined samples. This mask does not warp after producing multiple machined samples because it has fast photospeeds for mass production, ability to endure the chemical reactions for long time, capability to adhere with substrates, etc. The array of micro circular impressions on SU-8 2150 mask is shown in Figure 8a before machining. The used mask after machining of twenty six samples is shown in Figure 8b. So, SU-8 2150 photoresist has good efficacy for producing multiple high quality micro circular impressions economically using maskless EMM technique. Maskless EMM method is considered an alternative method instead of TMEMM process because through mask EMM process needs individual masking for each workpiece before machining.

Figure 9 depicts the micrograph of micro dimple pattern and SEM image of machined micro circular impression and it is fabricated with the specified parametric setting i.e. electrolyte of $\mathrm{NaCl}(0.17 \mathrm{M})+$ $\mathrm{NaNO}_{3}(0.11 \mathrm{M})$, frequency of $20 \mathrm{kHz}$, voltage of $8 \mathrm{~V}$, flow rate of $6.12 \mathrm{~m}^{3} / \mathrm{hr}$, duty ratio of $30 \%$, inter electrode gap of $50 \mu \mathrm{m}$ and machining time of 2 minutes. This array of micro circular impressions upholds more or less identical geometrical shape and size throughout the pattern because the combined electrolyte performs the uniform anodic dissolution for controlled current flux distribution. The depth is also homogeneous across the pattern due to higher anodic dissolution.

Three-dimensional view and two-dimensional profile of a small segment of micro circular impression are shown in Figure 10. The machining depth of micro circular impression is $24 \mu \mathrm{m}$. Figure 11 shows two-directional 

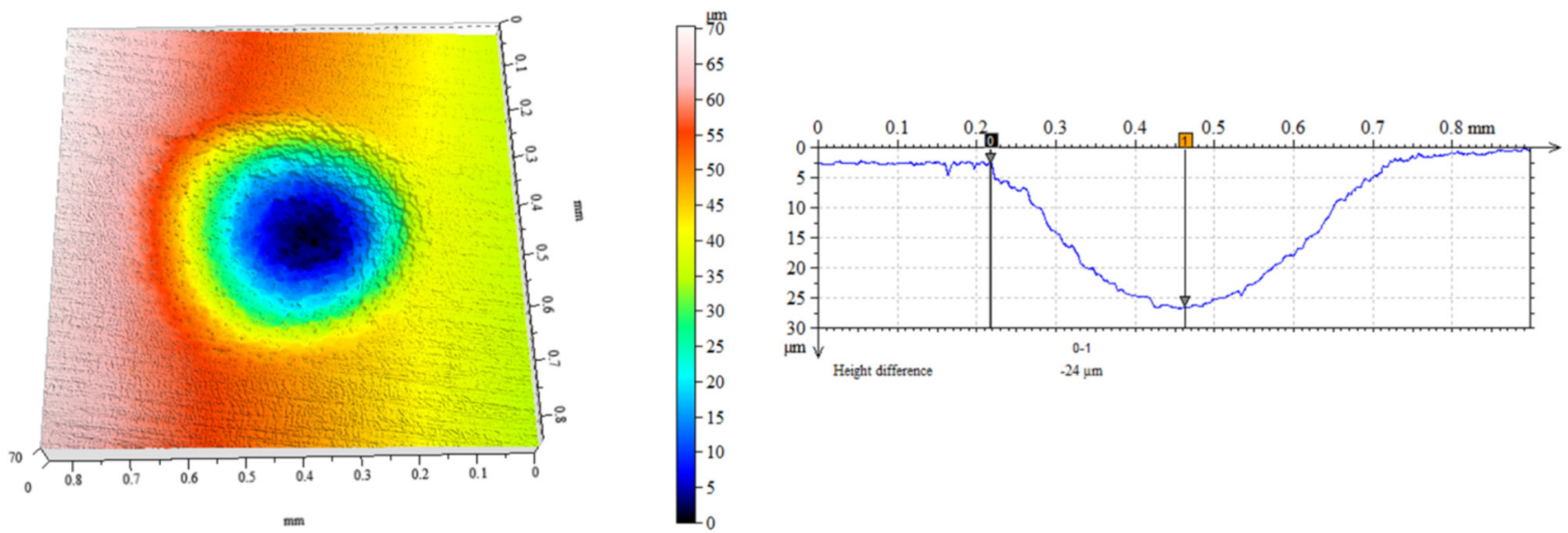

Fig. 10. $3 \mathrm{D}$ view and $2 \mathrm{D}$ depth profile of a micro circular impression generated by $\mathrm{NaCl}+\mathrm{NaNO}_{3}$.

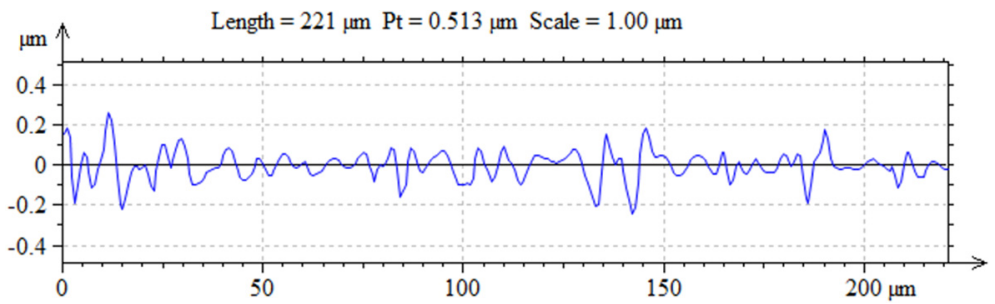

Fig. 11. 2D surface roughness profile of a micro circular impression generated by $\mathrm{NaCl}+\mathrm{NaNO}_{3}$.
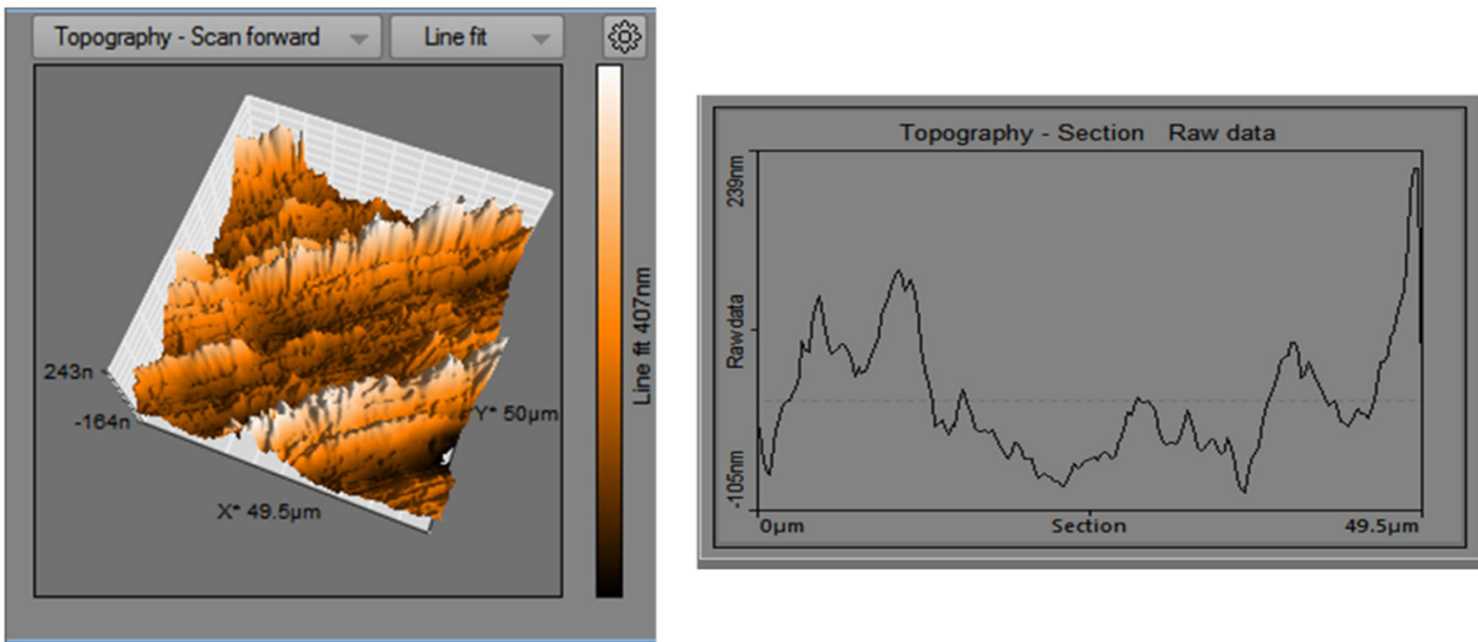

Fig. 12. $3 \mathrm{D}$ view and $2 \mathrm{D}$ profile of a micro circular impression generated by $\mathrm{NaCl}+\mathrm{NaNO}_{3}$.

surface roughness profile of a small segment of micro circular impression. The value of surface roughness of a small segment of micro circular impression is $0.0405 \mu \mathrm{m}$.

Three dimensional view and two-dimensional profile of a small segment of micro circular impression are shown in Figure 12. These figures are taken by Atomic Force Microscope (AFM). The values of root mean square $(R q)$, maximum profile peak height $(R p)$, maximum profile valley depth $\left(R_{v}\right)$ and surface roughness $\left(R_{a}\right)$ are $0.068 \mu \mathrm{m}$, $0.213 \mu \mathrm{m},-0.072 \mu \mathrm{m}$ and $0.052 \mu \mathrm{m}$.

\section{Conclusions}

A simple and unique texturing method of maskless EMM has been presented for the production of high quality array of micro circular impressions. In this process, single textured tool fabricates many machined micro circular patterns economically without masking of every individual workpiece before machining, which is more significant matter in industrial context. Effects of frequency and duty ratio are discussed on dimensional 
overcut and depth of micro circular pattern. The following conclusions have been summarized from experimental investigations:

- Maskless EMM is an alternative technique for the generation of multiple high quality arrays of micro circular impressions economically. A well planned experimental setup with vertical cross flow electrolyte system has been fabricated for producing good array of micro circular impressions with higher productivity. One masked patterned tool can produce more than twenty six textured samples using SU-8 2150 mask.

- The developed mathematical model is suitable for initial estimation of theoretical radial overcut and depth of micro circular pattern and validates the experimental results for three different electrolytes. The lowest standard deviation has been observed for $\mathrm{NaCl}+\mathrm{NaNO}_{3}$ electrolyte and this electrolyte maintains proper uniformity of the micro circular pattern than other two electrolytes.

- Machining with higher pulse frequency and lower duty ratio are suggested for better dimensional uniformity and controlled depth using $\mathrm{NaNO}_{3}, \mathrm{NaCl}$ and $\mathrm{NaNO}_{3}+\mathrm{NaCl}$ electrolytes. Only $\mathrm{NaNO}_{3}+\mathrm{NaCl}$ electrolyte is more appropriate to produce good array of micro circular impressions.

- Form the analysis of micrograph, the best machining parameters are pulse frequency of $20 \mathrm{kHz}$, duty ratio of $30 \%$ and electrolyte of $\mathrm{NaCl}(0.17 \mathrm{M})+\mathrm{NaNO}_{3}(0.11 \mathrm{M})$ and this parameter setting generates the uniform array of micro circular impressions having radial overcut of $23.31 \mu \mathrm{m}$ and machining depth of $14.1 \mu \mathrm{m}$.

Finally, this research study in the area of microelectrochemical texturing provides an alternative replacement and will accomplish different vital needs in the area of microsurface texturing. However, this research area still needs further investigation for better control of the tool and workpiece movement strategies in maskless EMM.

\section{References}

1. A.A.G. Bruzzone, H.L. Costa, P.M. Lonardo, D.A. Lucca, Advances in engineered surfaces for functional performance, CIRP Ann. 57 (2008) 750-769

2. X. Hao, L. Wang, Q. Wang, F. Guo, Y. Tang, Y. Ding, B. $\mathrm{Lu}$, Surface micro-texturing of metallic cylindrical surface with proximity rolling-exposure lithography and electrochemical micromachining, Appl. Surf. Sci. 257 (2011) 8906-8911
3. W. Li, W. Quandai, H. Xiuqing, D. Yucheng, L. Bingheng, Finite element simulation and experimental study on the through-mask electrochemical micromachining (EMM) Process. Int. J. Adv. Manuf. Tech. 51 (2010) 155-162

4. C. Madore, O. Piotrowski, D. Landolt, Through-mask electrochemical micromachining of titanium, J. Electrochem. Soc. 146 (1999) 2526-2532

5. G. Wang, H. Li, C. Zhang, D. Zhu, Improvement of machining consistency during through-mask electrochemical large-area machining, Chin. J. Aeronaut. 32 (2019) 1051-1058

6. D. Jin, K. Chun, E. Lee, Analysis of the current density characteristics in through-mask electrochemical micromachining (TMEMM) for fabrication of micro-impression arrays on invar alloy film, Chin. J. Aeronaut. 30 (2017) 1231-1241

7. S. Kunar, S. Mahata, B. Bhattacharyya, Micro dimple array fabrication by through mask electrochemical micromachining utilizing low-aspect ratio mask, J. Electrochem. Soc. 165 (2018) E129-E137

8. X. Zhang, N. Qu, Improvement in machining accuracy of micro-dimples fabricated in a sandwich-like electrochemical micromachining unit using a porous cathode, Int. J. Adv. Manuf. Technol. 99 (2018) 1661-1671

9. J. Mitchell-Smith, A. Speidel, A.T. Clare, Transitory electrochemical masking for precision jet processing techniques, J. Manuf. Process 31 (2018) 273-285

10. I. Schonenberger, S. Roy, Microscale pattern transfer without photolithography of substrates, Electrochim. Acta 51 (2005) 809-819

11. X.L. Chen, B.Y. Dong, C.Y. Zhang, M. Wu, Z.N. Guo, Jet electrochemical machining of micro dimples with conductive mask, J. Mater. Process. Technol. 257 (2018) 101-111

12. J.G. Parreira, C.A. Gallo, H.L. Costa, New advances on maskless electrochemical texturing (MECT) for tribological purposes, Surf. Coat. Technol. 212 (2012) 1-13

13. S. Kunar, S. Mahata, B. Bhattacharyya, Influence of electrochemical micromachining process parameters during fabrication of varactor micropattern, Int. J. Adv. Manuf. Technol. 96 (2018) 411-427

14. S. Kunar, B. Bhattacharyya, Fabrication of various micropatterns by maskless micro-electrochemical texturing, Manufact. Rev. 6 (2019) 6

15. S. Kunar, B. Bhattacharyya, Influence of various flow methods during fabrication of micro ellipse pattern by maskless electrochemical micromachining, J. Manuf. Process 35 (2018) 700-714

16. S. Kunar, B. Bhattacharyya, Effect of various masked patterned tools during micro-electrochemical texturing, Microsyst. Technol. 25 (2019) 1475-1492

17. H.L. Costa, I.M. Hutchings, Development of a maskless electrochemical texturing method, J. Mater. Process. Technol. 209 (2009) 3869-3878

Cite this article as: S. Kunar, E. Rajkeerthi, K. Mandal, B. Bhattacharyya, Fabrication of array of micro circular impressions using different electrolytes by maskless electrochemical micromachining, Manufacturing Rev. 7, 15 (2020) 